\title{
PADRE FRED GREEN SJ, RETRATO DE UN HOMBRE NOBLE
}

\author{
FATHER FRED GREEN SJ, PORTRAIT OF A NOBLE MANE
}

\section{Carlos Cuya Mamani $^{1}$}

\section{RESUMEN}

El artículo trata de la vida y obra del Padre Fred Green S.J., propulsor de un modelo de educación humanizadora basada en valores. Y propone un esbozo de interpretacion interdisciplinaria de su experiencia vital, basada en el altruismo y empatía que dieron sustento a su conciencia moral e hicieron de él un homo empathicus.

Palabras clave: homo empathicus, promotor de educación.

\section{ABSTRACT}

The article deals with the life and work of Father Fred Green SJ, promoter of a humanizing education based on values model. It proposes an outline of interdisciplinary interpretation of his life experience, founded on altruism and empathy that supported his moral conscience and made him a homo empathicus.

Keywords: homo empathicus, promoter of education.

\section{INTRODUCCIÓN}

"Hay hombres que luchan un día y son buenos. Hay otros que luchan un año y son mejores. Hay quienes luchan muchos años, y son muy buenos. Pero hay los que luchan toda la vida, esos son los imprescindibles", es una frase de Bertolt Brecht, que encaja bien en la vida del padre Fred Green Fernández SJ. Pocos son los hombres que encarnan una experiencia de vida como la suya. Aquellos que pertenecen a una estirpe de seres humanos universales que trascendiéndose a sí mismos entregan su vida a un ideal: servir a su prójimo, sin importar la raza, ideología o cualquier otra idea que etiquete al hombre. Hoy, a sus 93 años, su vida representa una rica experiencia humana tras haber sobrevivido a la terrible experiencia de una guerra mundial, su vocación de servicio que lo llevó a traspasar fronteras distantes y llegar a la Heroica Ciudad de Tacna donde se hizo "tacneño". La Orden Jesuita, a la que pertenece, registra también experiencias similares de la talla de Marie-Joseph Pierre Teilhard de Chardin, francés, quien vivió la traumática experiencia de la Primera Guerra Mundial y luego viaja a China donde desarrolla su vocación científica, en la paleontología; así como de Hugo Enomiya Lassalle, alemán, quien también vivió la experiencia de la Segunda Guerra Mundial y luego viajó a Japón, donde resultó herido por la bomba atómica de Hiroshima. Allí promovió la construcción de un templo por la Paz Mundial y descubrió el Zen para los cristianos que enseño hasta muy avanzada edad, dice al respecto: "en el Zen el alma va al encuentro de Dios hasta el límite de sus posibilidades".

Nuestra sociedad actual se caracteriza por ser una sociedad en crisis, víctima de la corrupción y el abuso del poder que finalmente beneficia a pocos que derrochan y desperdician la riqueza, víctima de la violencia y sus secuelas, del narcotráfico y la pobreza. Los que delinquen se han convertido en "ejemplos" a seguir. La sociedad necesita de modelos, dignos de imitar y así construir una comunidad saludable y armoniosa. Estos modelos pueden obedecer a lo que Campbell llama el mito del héroe. ¿Y quién es un héroe?. Para Campbell: "...un héroe es alguien que ha dado su vida por algo más grande que el mismo...". ¿Y cuál es eso grande o hazaña que hace el héroe?: "... hay dos tipos de hazaña. Una es la hazaña puramente física, en la que el héroe realiza un acto de valor en la batalla o salva una vida. El otro tipo de hazaña es espiritual, en la que el hombre aprende a experimentar el espectro supranormal de la vida espiritual humana y después vuelve con un mensaje..." (Campbell, 1991).

\footnotetext{
${ }^{1}$ Magister en Medicina. Docente de la Facultad de Medicina de la Universidad Nacional San Agustín de Arequipa-Perú. Correoelectrónico:carlosyovanicuya@yahoo.com.mx
} 


\section{La Vida y la Fistaria}

\section{Cuya, C. Padre Fred Green SJ, Retrato de un Hombre Noble}

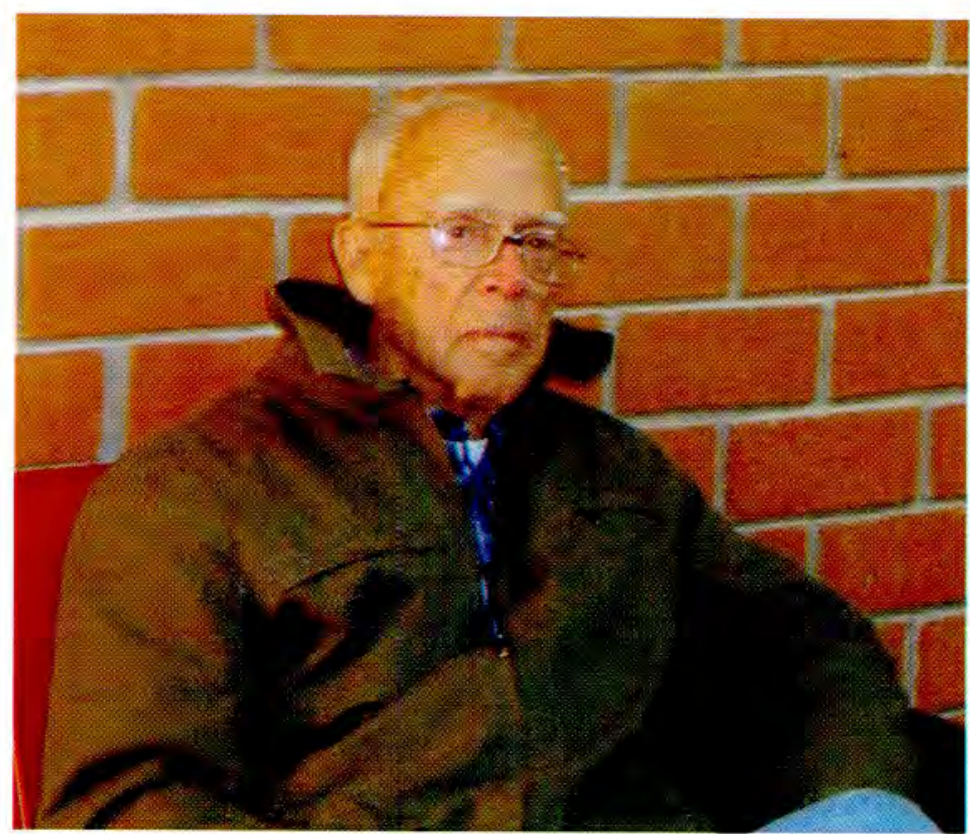

Figura 1. Padre Fred Green. Fotografía tomada en el mes de Agosto del 2014 durante la entrevista realizada en la casa de retiro de los padres jesuitas en Tacna.

También ese modelo a seguir encuadra bien en el concepto de Arquetipo de Jung (Alarco, 2011). Los arquetipos son los contenidos del inconsciente colectivo, es decir ciertas imágenes que se encuentran en las profundidades de la psique y ejercen un efecto "constelador", o sea motivador. Son en realidad los mitos mismos.

Estos modelos o arquetipos desencadenan acontecimientos vitales (Alarcón et al., 2005), término psiquiátrico que designa a "...cierto tipo peculiar de situaciones, de signo positivo o negativo, producidas activamente o vividas sin haberlo buscado en forma deliberada, que requieren del sujeto un trabajo psíquico adicional (concebido más que nada en términos de economía psíquica) y la puesta en funcionamiento de técnicas no habituales (concebidas más que nada en términos conductuales). De esta manera, en el transcurso de la vida existen acontecimientos vitales que se destacan por ser únicos (no pertenecen al orden de la cotidianidad), por estar ubicados en la experiencia temporal en donde dejan una impronta (permitiendo un antes y un después) y por exigir un esfuerzo adaptativo a la persona y de cuyo logro o fracaso concluirá en un triunfo o derrota sobre el reto.

La obra del padre Fred Green es amplia en el campo educativo y social, que bien merecería ser estudiada desde el punto de vista interdisciplinario: sociológico, antropológico, educativo, ético e inclusive neurocientífico. Ha servido de ejemplo y motivación, y suscitado innumerables acontecimientos vitales en miles de niños y jóvenes tacneños que hoy son ciudadanos y hombres de bien.
La psiquiatría y la psicología se han preocupado de estudiar al ser humano desde el punto de vista de la enfermedad, es así que Sigmund Freud lo estudia desde la neurosis, y poco se lo ha estudiado respecto al desarrollo armonioso de sus potencialidades. Solo Abraham Maslow, en forma pionera, analizó a aquellos seres humanos que tuvieron experiencias cumbre, es decir un estado de autorrealización. Mucho menos posible es encontrar estudios sobre seres humanos excepcionales que han trascendido su individualidad, y muestran características especiales que Leopoldo Chiappo, extinto psicólogo peruano de la Universidad Peruana Cayetano Heredia, ha llamado rasgos de la nobleza de ser hombre, cuando estudia en la Presencia espiritual de Honorio Delgado. Maestro de vida superior (León, 2010), a su maestro, el mismo Honorio Delgado, insigne psiquiatra de talla mundial.

Desde este punto de vista, el Padre Fred Green es también un "maestro de vida superior", es decir, "de la preeminencia de la espiritualidad entendida como nivel que eleva la humanización del hombre frente a la condición meramente animal de la vida" (León, 2010). Vida superior es, entonces, vida regida por el espíritu, vida que "cuando en la experiencia y en la aprehensión del mundo y en la acción y conducta empiezan a jugar motivaciones tales como la belleza, justicia, verdad, bien, amor, dignidad, cortesía, magnanimidad, ternura, comprensión, sutileza, consideración, veracidad, autenticidad, libertad" (León, 2010).

El presente artículo pretende describir una semblanza del Padre Fred Green haciendo hincapié en su vida y obra, en las ideas que sustentaron su 
quehacer apostólico a lo largo de casi medio siglo de labor por el prójimo, enriquecidos con el testimonio directo de su experiencia. Finalmente, fundamentamos su nobleza de ser hombre, es decir de hombre trascendente y de maestro de pedagogía universal, que educa con el ejemplo, utilizando las características que Leopoldo Chiappo define cuando analiza la obra de su maestro Honorio Delgado.

\section{VIDA Y OBRA (Colegio Cristo Rey, 1987)}

1922: Frederick Judd Green Fernández nace el 26 de Agosto en Hawai, de padre norteamericano y madre de ascendencia portorriqueña.

1946: En California, Estados Unidos de Norteamérica, ingresa al noviciado para ser sacerdote Jesuita.

1959: Llega a Tacna, el 17 de noviembre, a los 37 años, junto al padre Ernesto Mc Clear S.J., quien sería el primer superior jesuita en Tacna. El padre Green, se había ordenado sacerdote el año anterior. A fines de ese año, Monseñor Alfonso Zaplana Belliza, Obispo de Tacna y Moquegua, les propuso encargarse de la Vicaría (San Pedro Apóstol). Toma posesión de la Parroquia, el mismo Padre Green, por enfermedad del Padre Mc Clear, el primero de diciembre de ese año.

1961: Inicia su labor educativa como profesor de Religión en la Escuela Normal de Mujeres "Corazón de María" de Tacna.

1962: En el mes de Abril, comienza a funcionar el Colegio "Cristo Rey", en el patio de la Vicaría, la primera de sus obras. En ese año se lleva a cabo el Concilio Vaticano II, el cual influyó en la orientación educativa del colegio hacia una cultura de paz entre los pueblos y la justicia social. Bajo este influjo, se da importancia a la estrecha colaboración entre el colegio y el hogar, así como la incorporación de maestros laicos en la educación.

1964: Fundación de la Cooperativa Parroquial de San Pedro de Tacna.

1965: Inauguración del nuevo edificio del Colegio "Cristo Rey", 31 de Julio, en la zona de Para, con 12 aulas de primaria, administración y convento. En esta obra, el Padre Green participa activamente.

1969: Edita METAS, serie de folletos, donde da a conocer el ideario de su misión. Participación activa de los padres de familia en la educación de sus hijos, para formar seres humanos responsables y así puedan enfrentarse con los retos del mundo moderno, a través del desarrollo físico, afectivo, intelectual y social. Propone la integración social, a través de la convivencia, donde todas las clases sociales aprendan a vivir y trabajar juntas, con caridad y justicia. El modelo para ello es la de Jesucristo: "No he venido a ser servido sino a servir". Para ello propicia el ingreso de
"Cristo Rey", mediante becas y otras diversas ayudas.

1971: Con el Colegio "Cristo Rey", apoya activamente la huelga del Magisterio Nacional. La razón de ello fue la postergación económica de los maestros durante el Gobierno Militar del General Juan Velasco Alvarado (en el poder desde el golpe de Estado de 1968). En apoyo al magisterio peruano el Padre Fred Green y el personal docente del colegio a su cargo, envían una carta al Gral. Velasco, copia de la cual es también entregada al Diario "Correo" de Tacna. En ella defiende el reclamo y la considera justa “...porque ganan un sueldo de hambre...". Considera también la necesidad de un cambio en las estructuras económicas tradicionales, mencionando que "...la Revolución tiene que seguir, cueste lo que cueste, para que haya un Perú más justo, para que haya una distribución más equitativa de los bienes materiales, para que todos tengan la oportunidad de vivir con dignidad humana. Creo que la mayoría de los maestros en el Perú apoyamos estas metas de la Revolución...". Es claro también en afirmar que "...una revolución requiere sacrificios. Pero somos débiles, los sacrificios nos cuestan. Tenemos que ser motivados, inspirados por líderes que sean los primeros en sacrificarse. Queremos líderes cristianos que han aceptado el reto de Cristo: el que quiera ser grande entre ustedes, debe servir a los demás, el que quiera ser el primero, debe ser el siervo de todos...". Luego expone una de las razones de la injusticia: "...Hemos puesto gran esperanza en esta Revolución. Por favor, no nos fallen. !Inspirennos! Ya han escandalizado a muchos con sus buenos sueldos y privilegios. Pero no es tarde para cambiar. Uds. dicen que no pueden aumentar los sueldos de nuestros colegas. Entonces deben estar dispuestos a correr la misma suerte. Que el alférez deje de ganar más de $S$ / 10,000 al mes y acepte los S/ 4,000 del maestro. Entonces, le aseguramos Sr. Presidente, nuestros colegas aceptaran su suerte. No reclamarán más y aún se sacrificarán más. Esto es lo que necesita el Perú: solidaridad en el sacrificio. No se construye nada que vale la pena, sino a base de sacrificios... " Esta carta tuvo honda acogida a nivel nacional, y ayudó a promover una solidaridad inusitada hacia los maestros. La carta se publicó en diarios a nivel nacional y fue copiada en mimeógrafo, repartiéndose por las calles de muchas ciudades del país. Se declaran en huelga indefinida 120,000 maestros de todos los niveles de educación. El padre Green escribe en vísperas de la huelga: “...en el caso del Magisterio Peruano, creo que se están agotando todos los otros recursos a su alcance $y$ no parece haber otro remedio...lucharemos con dignidad, sin violencia, sin rencor, sin sembrar odios ni desuniones. Nuestra causa es justa, por lo tanto Dios nos tiene que ayudar... ". La protesta de los maestros en 
familia, de las mujeres tacneñas y no fue politizada, razón por la cual no tuvo la misma acogida en huelgas posteriores. Finalmente, la huelga fue suspendida debido a que el gobierno accedió a las peticiones aceptables de los maestros. Pero ello constituyó, en cierta forma, "un foco de oposición al Gobierno Revolucionario" que era necesario eliminar, por lo que el Gral. Velasco anunció en una reunión del Consejo de Ministros su decisión de expulsar del país al padre Green. Para ello, aprovechó el inicio de las vacaciones escolares, Enero de 1972. Una serie de negociaciones del más alto nivel impidieron esta expulsión.

Ese mismo año, se crea el "Mes de Servicio Social", una modalidad de trabajo social que tiene como objeto llevar a la práctica la preparación del estudiante en la ayuda al prójimo, es decir, una "experiencia directa, personal y organizada de contacto con los pobres y de servicio a los demás necesitados". Ejemplo de esta labor es la construcción de escuelas o postas médicas en pueblos jóvenes o comunidades campesinas de Tacna. Grupos de 35 a 40 alumnos del cuarto año de secundaria, acompañados por asesores (profesores y sacerdotes jesuitas) se dividen en 3 o 4 equipos y realizan labores de construcción, catequesis de niños, limpieza entre otras, para poder conocer la pobreza, las difíciles situaciones de trabajo, los problemas de salud y otros sufrimientos por lo que pasan las familias peruanas pobres. Esta labor también la realizan jóvenes alumnos de la Institución Educativa "Miguel Pro", que años más tarde fundará el mismo.

1973: El padre Green participa en la liberación y reposición a su centro educativo de profesores del Colegio "Cristo Rey" que participaban en las luchas magisteriales.

1974: Bajo el lema "Ser hombres para los demás" propone la formación de hombres que amen la justicia y luchen por los derechos del oprimido.

1975: Dedica la marcha, compuesta por él, “ $\boldsymbol{E} \boldsymbol{l}$ Soldado de la Paz" al Batallón Perú que viajó en ese entonces al Medio Oriente, en misión de preservar la paz.

1977: Edita "SEMBRADORES", folleto dirigido a los maestros, en donde sienta las bases de la labor docente, fruto de su experiencia misional. En este documento hace notar la tarea noble y difícil en la formación humanística de los niños y jóvenes: "...si el profesor o tutor no es un cristiano convencido, un apóstol cuya luz brille entre los demás, no será el influjo positivo que hará cambiar a sus alumnos. Con los jóvenes, la manera de vivir, las obras de uno, dicen mucho más que sus palabras...". Insta a formar hombre maduros en lo afectivo, intelectual y social, y "...así cristianos convencidos que influirán en su ambiente, hombres nuevos que serán agentes de cambio, amor y justicia para enfrentar las dificultades, los peligros y el favoritismo. Propone que "...la verdadera educación consiste, sobre todo, en enseñar a pensar..." a través del estudio, los trabajos prácticos, el deporte y otras actividades, para que "...sepan expresarse y comunicarse por la palabra hablada y escrita. Sin esta expresión, les será difícil influir en los demás...". Todo ello con una finalidad suprema: la formación de una verdadera conciencia social, un amor a la justicia. Para afianzar ello, añade: "...el profesor creará en sus muchachos una conciencia de las mayorías oprimidas y subalimentadas. Los ayudará a vivir esta problemática al mismo tiempo que los prepare para la lucha definitiva por un mundo más justo...". Finalmente, respecto al desarrollo de la conciencia social dice: "...lo que se pretende es un hombre comprometido con los problemas y aspiraciones que plantea el cambio social; capaz de dominar las técnicas, pero poniéndolas al servicio de un ideal humanista; que lucha por una comunidad más justa donde la dignidad de un hombre no sea sacrificada a los fines económicos de una sociedad materialista; convencido de que no existe más que una actitud que vale la pena: la de elevarse, elevando a los demás...".

En relación a las ideas prácticas sobre el trato del maestro, incide en el respeto a la condición social de los alumnos más pobres, en la exigencia en entrega y puntualidad de las tareas encomendadas a los alumnos. Dice: "...nunca aceptaré trabajos mediocres. Tengo que formar hombres responsables y disciplinados. Los alumnos que no quieran colaborar con esta formación tendrán que ser despedidos..."

No deja de lado la formación espiritual del ser humano, es claro al decir "...he de tener profunda convicción de mi cristianismo y mostrárselo al alumno con gran transparencia...la oración será elemento esencial de mi vida. Mi trabajo con los alumnos debe ser materia de frecuente oración y reflexión..."

1979: No respalda ninguna huelga del magisterio. Habló de "...otro motivo serio para reflexionar sobre la justicia de una huelga en este momento. A pesar de ciertos logros del SUTEP en bien del docente peruano, es necesario que el maestro se dé cuenta del camino por el cual este sindicato quiere llevarlo. En sus estatutos, el SUTEP revela con claridad que tiene fines políticos. Además, declara abiertamente que su política se basa en el principio universal de la lucha de clases..."

1986: Creación del "Centro Cristo Rey del Niño Trabajador", donde se presta atención a los niños que trabajan. Más tarde, toma el nombre de "Centro Cristo Rey del niño y del adolescente". Además en su local funciona un centro de atención de salud, en donde médicos ex alumnos del Colegio "Cristo Rey" brindan 
1987: El 7 de Julio, recibe el reconocimiento del Estado mediante las Palmas Magisteriales de manos del Ministro de Educación Grover Pango Vildoso.

Celebra los 25 años de fundación del Colegio "Cristo Rey" y deja la dirección del mismo.

1989: Trabaja conjuntamente con Hábitat para la Humanidad para propiciar la construcción de viviendas para familias pobres; siendo su filosofía de trabajo el ayudar a fomentar un sentido de comunidad, la fe y el servicio entre sus residentes. El lugar elegido fue una zona árida a $10 \mathrm{~km}$. al sur de Tacna, que fue llamada Hábitat Ciudad de Dios.

Ese mismo año participa como Promotor en la creación del Colegio "Fe y Alegría" No 40 de Tacna.

1992: Funda el Colegio "Miguel Pro", que en sus comienzos funciono en casas de Hábitat Ciudad de Dios. Propicia la educación de niños y jóvenes con la participación de las familias, bajo los valores de justicia social.

2005: En Agosto, recibe del Gobierno Regional de Tacna, la Condecoración Jorge Basadre Grohmann por su labor en la ciudad de Tacna.

2008: Reconocimiento de la Municipalidad Provincial de Tacna por su labor social.

2013: Recibe el Premio por la Paz 2013 del Ministerio de la Mujer y Poblaciones Vulnerables, en la categoría Sociedad Civil, subcategoría Persona Natural.

2014: Es Párroco de la Capilla Hábitat Ciudad de Dios y Promotor del Colegio "Miguel Pro".

\section{UN MODELO DE EDUCACIÓN HUMANIZADORA MEDIANTE EL EJEMPLO}

Como se dijo arriba, los nuevos vientos de renovación de la iglesia católica, dada por el Concilio Vaticano II dieron una orientación en la educación hacia una cultura de paz y a la justicia social, en donde se daba importancia a la estrecha colaboración entre la escuela y el hogar. Fue importante el objetivo de formar seres humanos con conciencia social sensible a las injusticias de la sociedad. Es así que a partir de 1974 propone el lema educativo "ser hombres para los demás". En la práctica esto se refleja en las oportunidades educativas que se dieron a niños $\mathrm{y}$ jóvenes marginados, obteniéndose "una comunicación real y una aceptación de unos a otros por lo que son, no por lo que tienen". Esto fue un adelanto en su época, de lo que ahora se llama inclusión social desde la perspectiva del desarrollo humano, que se define como el " conjunto de lazos sociales que permite a las personas aspirar y lograr la vida que valoran y que, al mismo tiempo, estas sean valoradas en su sociedad de pertenencia".

\section{EL PADRE FRED GREEN Y LA NOBLEZA DE SER HOMBRE.}

Valorar la vida y la trayectoria de un ser humano excepcional como la del Padre Fred Green, así como de su obra, se torna difícil, debido a que no existen parámetros definidos para evaluar el perfil vital de personas de sus características. Por esta razón hemos recurrido al aporte de Leopoldo Chiappo, connotado psicólogo, discípulo del Dr. Honorio Delgado, luminaria de la psiquiatría peruana, quien describe los rasgos de la Nobleza de Ser Hombre (Chiappo, 1998). Intentamos hacer un aporte comparativo del Padre Green con estos rasgos.

\section{- La elevación del individuo a la condición de persona.}

Esto quiere decir la inserción del organismo psicofísico del animal humano en el nivel personal del ser que lo hace capaz de captar y realizar valores superiores de carácter espiritual. ¿Cuáles son estos valores? Son el bien, la justicia, la verdad, la belleza, la inteligencia, la razón, el amor, que hacen al hombre un ser radicalmente bondadoso, auténticamente justo, veraz, amante de los bello y esplendoroso, inteligente, razonable y capaz de amor, amor que es raíz, tronco, tallo, rama, hoja, flor y fruto de la vida noble.

Uno de los valores superiores más destacables en la obra del Padre Fred Green es el ALTRUISMO, máxima expresión de la EMPATÍA (homo empathicus), es decir, aquella diligencia en procurar el bien ajeno aun a costa del propio, a través del amor que hace de él una persona bondadosa. Basta con observar la amplitud de su obra signada por su dedicación y entrega a los niños y jóvenes a lo largo de su vida. El mismo lo expresa de la siguiente manera: “...el que quiera ser grande entre ustedes, debe servir a los demás, el que quiere ser el primero, debe ser siervo de todos..."

\section{- Sensibilidad fina}

“...Que eleva la relación con el mundo natural por la capacidad de amar y compenetrarse con la naturaleza, con sentimiento de pertenencia, sentimiento de paisaje y de la lozanía vegetal. Altura en la relación con el mundo humano por la cortesía y la gentileza, el respeto a la majestad de la persona, la capacidad de simpatía profunda..."

El respeto a la vida humana, encarnada en la atención a los niños y jóvenes especialmente a los más vulnerables, denota en él sensibilidad frente al sufriente. En la práctica esto se evidencia cuando crea el "Mes de Servicio Social", una experiencia directa, personal y organizada de contacto con los pobres y de servicio a los más necesitados

- Ánimo dirigido a lo excelente. 


\section{La Vida y la Histaria}

Cuya, C. Padre Fred Green SJ, Retrato de un Hombre Noble

"Es en la dirección selectiva hacia los valores superiores, hacia lo supremo, a las formas exquisitas, a los altos niveles de la calidad y de la belleza en la naturaleza, en el arte en la vida humana, cuándo y dónde se realiza la forma y el nivel de la vida noble como sublime posibilidad ofrecida a la realización humana de la vida. Es que en el fondo de lo que se trata es de sutilizar las diferentes y múltiples maneras de darse la experiencia humana y las formas del devenir para que adquieran la transparencia necesaria a la manifestación de lo supremo. Es así entonces que la vida en el tiempo deviene gloriosa, en tanto es manifestación epifánica y luminosa de lo divino..."

"...Esta orientación que eleva y afina la experiencia humana, constituye rasgo principal de un impulso ascendente hacia la divinización, con lo que el hombre logra la plenitud y en último término llega a dar sentido a la existencia y con ello quizá descubrir la fuente de las delicias de la vida. En este ánimo dirigido a lo excelente se vislumbra, a mi parecer, una cierta bienaventuranza, una interna capacidad de felicidad, a pesar de todos los hechos adversos y contradictorios, de todas las miserias y dolores..."

Fija el ideal de su labor, cuando plantea que la verdadera educación consiste, sobre todo, en enseñar a pensar. Todo ello con una finalidad: la formación de

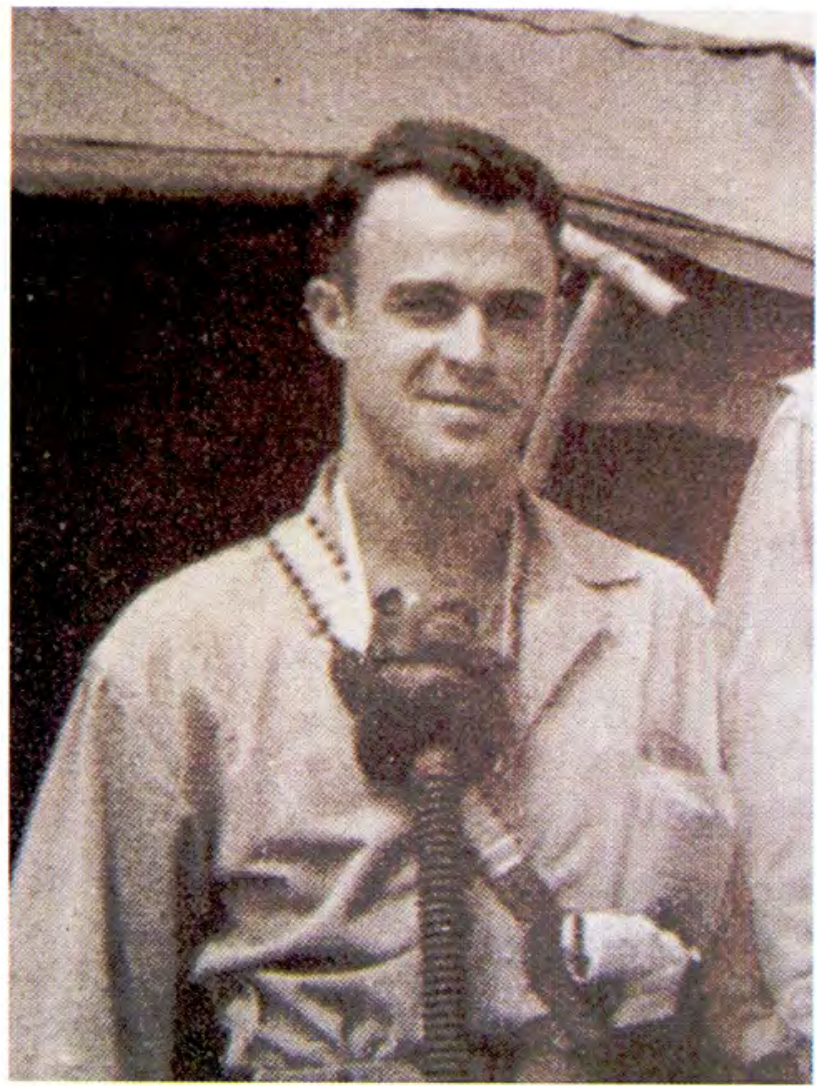

Figura 2. Durante la Segunda Guerra Mundial, como piloto de avión en misión de combate. una verdadera conciencia social, un amor a la justicia.

\section{- Voluntad abnegada.}

"...Rasgo de la nobleza del vivir altamente humano es el desprendimiento, la carencia de avidez interesada en el propio provecho. Honorio escribe sobre "la voluntad abnegada de hacer obra por la obra misma" y con ello define un rasgo de nobleza del ser humano en cuanto se entrega con esmero y sin más recompensa que la acción misma por amor a la perfección de la obra, olvidando de si amorosamente entregado a la perfecta realización de la acción en sí misma..."

Medio siglo dedicado a la formación y educación de generaciones de seres humanos, con una entrega llena de esmero y sin esperar recompensa alguna. Prueba de ello es la austeridad en que ha vivido a lo largo de su vida apostólica. La frase "no he venido a ser servido sino a servir", muestra el alto compromiso de su entrega.

\section{- Porte congenial con la grandeza y la excepción. \\ "...La recepción y realización por las personas} de aquello que por su grandeza es raro permite, espontáneamente, la distinción, la excepción de lo

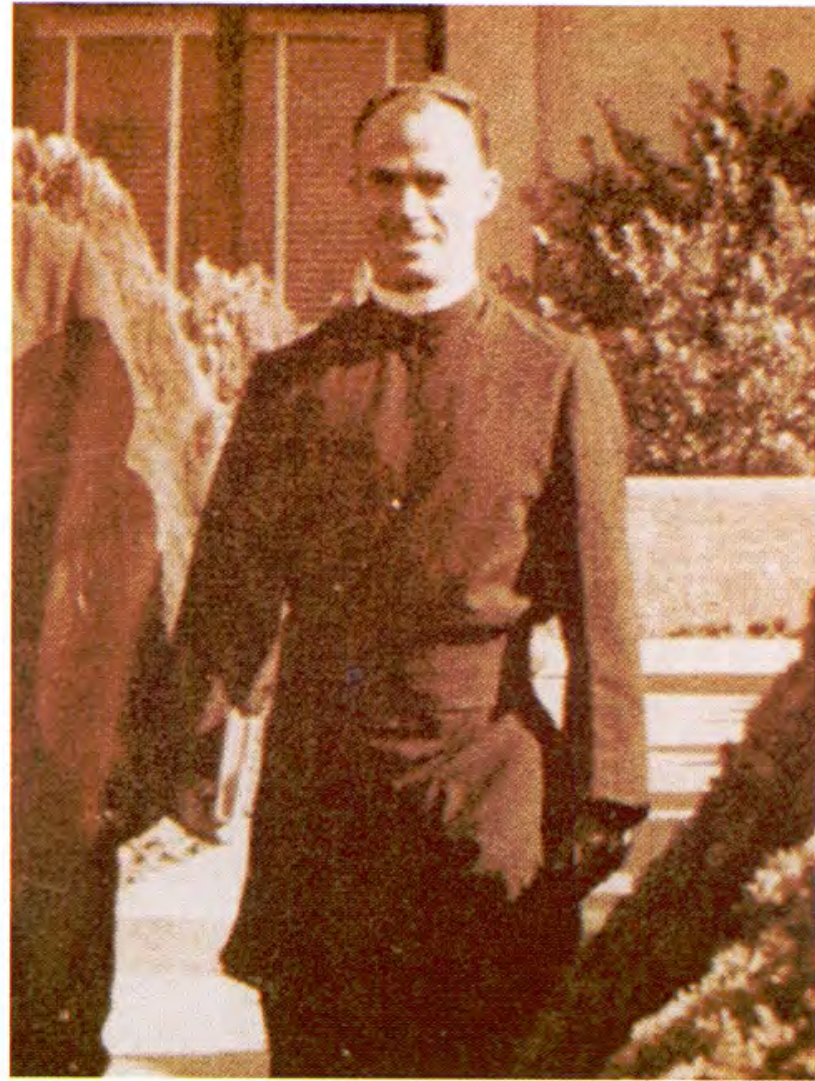

Figura 3. En los primeros años de su llegada a Tacna, como sacerdote Jesuita. 
sin pretenderlo, pues tal nobleza es auténtica y está lejos de la ficción y el amaneramiento y naturalmente del prurito de ser diferente. Hay un círculo virtuoso entre la elevación objetiva de los valores y el porte congenialmente elevado de quienes los estiman y realizan. Esto es lo que se llama congenialidad de la persona respecto de la grandeza y la excepción. Cuanto más alto y más raro el valor más elevado y más distinguido es el porte de la persona que lo aprecia y realiza..."

La realización del altruismo como valor, llevado a la práctica en la vida educativa, le da ese carácter de grandeza y excepción.

\section{ESBOZ O DE INTERPRETACIÓN INTERDISCIPLINARIA DE LA EXPERIENCIA VITAL DEL PADRE FRED GREEN S.J.}

"...Nacimos en un mundo en el que nos aguarda la alienación. Somos hombres en potencia, pero nos hallamos en estado de alienación y este estado no es simplemente un sistema natural. Para que la alienación sea nuestro destino actual, se requiere una violencia atroz, perpretada por seres humanos contra seres humanos...". Lo que denominamos "normal" es un producto de represiones, negaciones, escisiones,

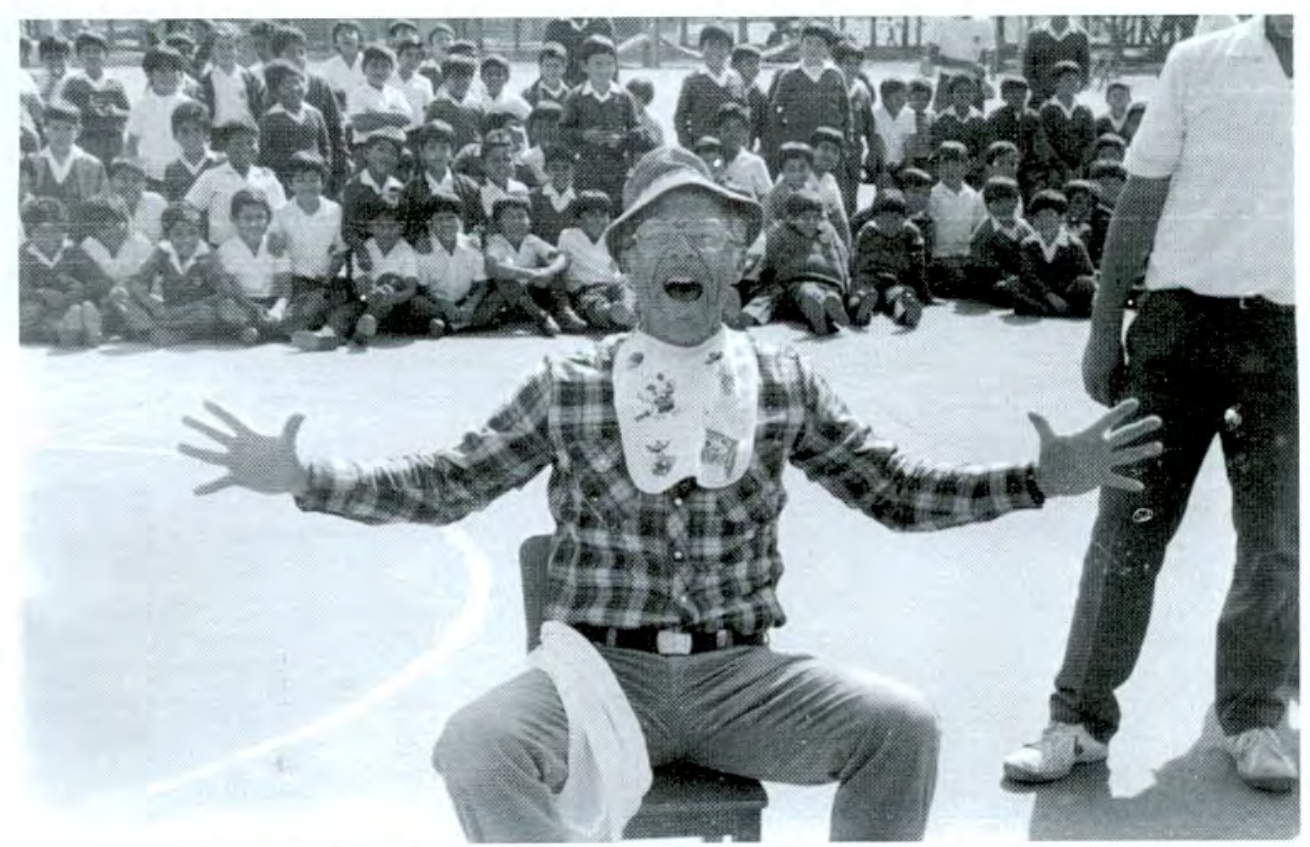

Figura 4. Durante una actuación ante alumnos del Colegio Cristo Rey

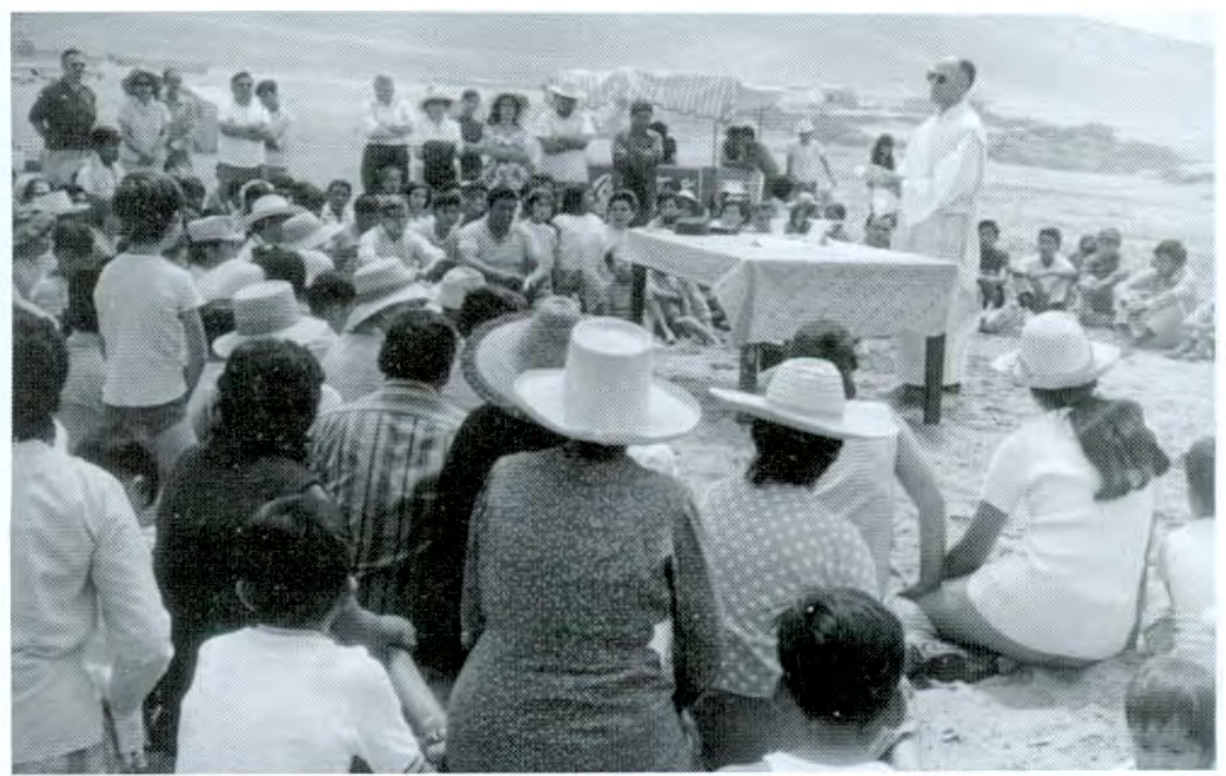

Figura 5. El Padre Fred Green con padres de familia del Colegio Cristo Rey, allá por los años 60. 
proyecciones, introyecciones y otras formas de acción destructora sobre la experiencia. Está radicalmente extrañado de la naturaleza de la estructura del ser...". "...La condición de alienado, dormido, inconsciente, loco, es la condición del hombre normal...". "...La sociedad tiene un elevado concepto del hombre normal; educa a los niños para que se pierdan y vuelvan absurdos y, de este modo, sean normales...". "En los últimos cincuenta años, las personas normales mataron alrededor de 100000000 de sus congéneres normales...". "...Ni siquiera somos capaces de pensar apropiadamente sobre una conducta que está al borde del aniquilamiento. Pero pensamos menos de lo que sabemos; sabemos menos de lo que amamos; y amamos muchísimo menos de lo que existe. Y precisamente, en esta medida, somos tanto menos de lo que somos..."

"No obstante, a falta de otra cosa, cada vez que nace una nueva criatura existe una posibilidad de indulto. Cada niño es un nuevo ser, un profeta en potencia, un nuevo príncipe espiritual, un nuevo chispazo de luz, arrojado a la oscuridad exterior. ¿Quiénes somos nosotros para decidir qué es y qué no es lo irremediable?..." (Laing, 1973). Estos son fragmentos de la obra "Experiencia y alienación en la vida contemporánea" de Ronald Laing, representante de la antipsiquiatría en los años 60, la cual describe las condiciones de vida del hombre contemporáneo y el camino que lo conduce a la enfermedad mental. Nos muestra la perspectiva temporal en la cual se desarrolla la experiencia vital del Padre Fred Green, es decir de una sociedad en grave crisis. Nos encontramos en la más importante encrucijada de la historia de la humanidad y por primera vez en su evolución las causas de esta crisis son nuestra propia obra. Destacan: la destrucción de ecosistemas, la pobreza absoluta de miles de millones de personas, y las amenazas ininterrumpidas del militarismo y la guerra. Aunado al narcotráfico y la corrupción, se ha creado una sociedad enferma, psicótica que es necesario desenmascarar.

Estas ideas cobran inusitada actualidad, y nos ayudan a explicar la vocación educativa asumida por el Padre Fred Green. Como todo humano tiene la oportunidad, el Padre Green asumió esa posibilidad de indulto, a la que hace referencia Laing, al asumir el compromiso educativo para con los niños y jóvenes tacneños, razón de su misión humanitaria. Dos experiencias cruciales deben considerarse para ello. La primera, es la experiencia de la Segunda Guerra Mundial que vivió el Padre Green. Cuantas muertes habrá imaginado luego de cada misión de combate, cuanto sentimiento de culpa habrá dejado marcado en su cerebro un circuito de memoria traumática. Este tipo de memoria parecida a una huella biológica no es inexorable, cambia en función de la experiencia haciendo que el cerebro reaccione de forma diferente.
Cualquier trauma modifica el funcionamiento cerebral: la metilación del ADN y la aparición de histonas son las alteraciones más frecuentes, según la epigenética (Carey, 2011). Sin embargo, es importante mencionar, que el desenlace de un hecho traumático, como la guerra, puede ser la enfermedad mental, enfrentarse a la muerte y al sufrimiento puede desorganizar el estado homeostático de un ser vivo, pero los dos factores de protección más valiosos son el apego seguro y la posibilidad de verbalizar. Un ser humano que durante los primeros meses de vida, ha recibido la impronta de un apego seguro es más difícil de herir que otro que no tuvo esa oportunidad. Además, el hecho de ser capaz de hacerse una representación verbal de lo que nos ha sucedido y de hallar a alguien a quien dirigir ese relato facilita el control emocional (Cyrulnik, 2013). Es probable que eso haya ocurrido en el Padre Green, un apego seguro en la infancia y la oportunidad de verbalizar su experiencia cuando encuentra la Compañía de Jesús, a instancias del consejo que el diera el capellan de su unidad de combate y otros religiosos, en donde vuelca su llamado espiritual.

La segunda experiencia crucial, es la experiencia de la guerra con Chile que vivió Tacna. Cuando el Padre Green llegó a esta ciudad, todavía ella vivía las consecuencias traumáticas de la guerra, signadas por el abandono y el olvido del estado peruano ante sus necesidades, y sobretodo a la falta de reconocimiento a su entrega en mantener el patriotismo y la peruanidad a costa de un sufrimiento traumático no valorado en toda su dimensión. En suma, podemos ver dos experiencias que tuvieron en común: la guerra, de ahí el amor que prodigó el Padre Green a Tacna mediante su obra, y el amor que prodigó Tacna al Padre Green, al comprender su sufrimiento.

Para comprender el por qué se da esta experiencia tan genuina de la obra del Padre Green tenemos que recurrir a dos conceptos importantes: el ALTRUISMO y la EMPATÍA. El altruismo se define como la "diligencia en procurar el bien ajeno aun a costa del propio" o también como un "fenómeno por el que algunos genes o individuos de la misma especie benefician a otros a costa de sí mismos" (según el diccionario de la Real Academia Española, $22^{\text {a }}$ y $23^{\text {a }}$ edición, respectivamente (Dugatkin, 2007)). Por otro lado, empatía es nuestra capacidad de identificar lo que otra persona piensa o siente $y$ responder ante sus pensamientos y sentimientos con una emoción adecuada (Baron-Cohen, 2011). O también podemos definirla como la capacidad de imaginar la situación del otro, tomando con ello la perspectiva de ese otro. Según la primera definición podemos encontrar que existen, al menos, dos fases durante la empatía: reconocimiento y respuesta. Las dos son necesarias y si se tiene la 
manera. La empatía no sólo requiere ser capaz de reconocer los sentimientos y los pensamientos de la otra persona, sino también de responder a ellos con una emoción adecuada. La empatía sigue un proceso evolutivo ontogénico, siendo la forma más avanzada de respuesta empática la capacidad de sentir como propio el sufrimiento de grupos de personas e incluso de otras especies. Cuando la empatía se universaliza hasta abarcar grupos enteros y categorías de seres se acerca a la noción de una conciencia universal (Rifkin, 2010).

Por otro lado, el altruismo es la manifestación extrema de la empatía, es la expresión de empatía más desarrollada; y en el fondo, el desarrollo de la empatía y el desarrollo de un sentido moral son lo mismo. Vemos, por tanto, que la vocación del Padre Green tiene que ver con un sentido ético y moral y lo importante es poder desentrañar cómo se desarrollo esta genuina capacidad empática. Esta depende del funcionamiento de un circuito especial del cerebro: el circuito de la empatía. La neurociencia, mediante los estudios de neuroimagen, especialmente de la resonancia magnético nuclear funcional (RMNf), está permitiendo disponer de las áreas del cerebro que desempeñan una labor importante a la hora de empatizar. Se conoce de que existen, por lo menos, hasta diez regiones interconectadas en el cerebro que participan en la empatía. Estas son: corteza prefrontal medial, corteza orbitofrontal, opérculo frontal, circunvolución frontal inferior, corteza cingulada anterior e ínsula anterior, unión temporoparietal, surco temporal superior, corteza somatosensorial, lóbulo parietal inferior y surco parietal inferior, y finalmente la amígdala. Estas regiones varían su actividad en función del nivel de empatía de cada persona. Es importante señalar aquí también la importancia de las neuronas espejo (Rizzolatti, 2006) en el desarrollo de la empatía. Lo más sorprendente, a decir de Rizzolatti, quien las descubrió, es que nos "...permiten captar la mente de otros, pero no mediante el razonamiento conceptual, sino por medio de la simulación directa. Sintiendo, no pensando..."

Seguidamente, es importante analizar que factores propician un desarrollo armónico de las áreas cerebrales relacionadas con la empatía descritas. Este desarrollo se basa en una adecuada base anatómica y funcional que tiene como sustento la información genética, aunque no determinante, mediada por interacciones ambientales de crucial importancia y que nos hace decir que el desarrollo cerebral no está conectado al genoma de cada individuo.

¿Qué factores ambientales influenciaron en el desarrollo armonioso del circuito cerebral de la empatía en el Padre Green?. Estos factores son: la seguridad del apego adecuado, el juego, la imaginación, el ejército norteamericano, la compañía de jesus. Como sabemos, John Bowlby, psicoanalista y psiquiatra infantil, estudió el rechazo por parte de los padres, desarrollando de esta manera la teoría del apego (Geenen, 2014; Moneta, 2009). Según Bowlby, el niño utiliza a su cuidador como una "base segura" desde la que explorar, y siente que cuando se aleja de su padre o de su madre, puede volver a ellos para "reabastecerse emocionalmente". El cariño del cuidador al elogiar, confortar y ofrecer un sentimiento de seguridad, ayuda al niño a manejar su ansiedad, desarrollar seguridad en si mismo y confiar en la seguridad de la relación. Lo que el cuidador da a un niño durante los primeros años de vida, tan críticos, es como un tesoro interno, un regalo muy valioso. El niño llevará ese tesoro interno durante toda su vida y es lo que dará fuerza a la persona para lidiar con los desafíos, la capacidad de recuperarse de los problemas de la vida y la capacidad de mostrar cariño, gozar de la intimidad en las relaciones con los demás. Es probable que el padre o la madre del Padre Green o uno de ellos, tuviera un alto nivel de empatía, lo que permitió el desarrollo de un apego seguro.

El juego desempeña un papel esencial en el desarrollo de la empatía, es el medio para crear apego, confianza, afecto, atención y vínculos sociales durante el crecimiento y para propiciar la sociabilidad en la vida adulta (Maturana y Verden-Zoller, 2013; Huizinga, 1972). Se ha erigido en un aspecto decisivo del desarrollo del ser humano. Cuanta importancia habrán dado los padres de Fred Green y su entorno más proximo, al juego durante su infancia. Ese entorno de juego es donde se aprende a ser empático. Es ahí donde se da lugar a la imaginación al intentar meterse en otros personajes, asumiendo roles y contextos para sentir, pensar y actuar como se creería que lo harían esos personajes. La imaginación, que se expresa a través del juego, permite el desarrollo de la conciencia empática (Vigotski, 2008).

Mediante el juego incorporamos a nuestro ser un mundo imaginado. $\mathrm{Y}$ este proceso de imaginar nos permite reunir experiencias corporales, abstracciones y emociones en un solo lugar: la mente empática. De esta manera, la imaginación humana es al unísono emocional y cognitiva.

La clave para que los impulsos empáticos innatos se transformen en respuestas empáticas desarrolladas tiene que ver con naturaleza de la disciplina educativa dada. La mejor manera de desarrollar el potencial empatico de un niño es hacer uso de la inducción, un método por el que los progenitores hacen ver el punto de vista del otro y dejan claro que la conducta del niño le ha hecho sufrir. Generar una sensación de culpa y remordimiento, y un sincero deseo de reparar el daño causado es importante. Lo que la disciplina por inducción enseña al niño constituye la base de la moralidad humana: responsabilidad por los actos propios, compasión, voluntad de ayudar y confortar a los demás, y un 
sentido adecuado de la justicia y el juego limpio. Esta forma de educación difiere de aquella en que se hace sentir vergüenza al niño una conducta equivocada. La vergüenza denigra al ser de la persona y hace que se sienta despreciable. Es muy probable que el Padre Green haya recibido una disciplina educativa por inducción en su entorno más cercano.

Más tarde, en el desarrollo ontogénico de su niñez fue importante el respeto a las normas sociales y posteriormente la enorme influencia que ejercieron instituciones como las Fuerzas Armadas norteamericanas y la Compañía de Jesús, las cuales se constituyeron en "nichos culturales" para la expresión de su conciencia empática y altruismo.

Honda motivación debe haber ocasionado en el Padre Green el mensaje de Jesús, ese impulso empático que se ha extendido hasta nuestra época, especialmente cuando pide a los seres humanos que hagan algo inimaginable: amar a sus enemigos, la expresión suprema de la compasión y la empatía universales.

\section{UN TESTIMONIO VIVO DE SU EXPERIENCIA}

En Agosto de este año 2014 entrevistamos al Padre Fred Green. Nos recibió en la casa de retiro de los Jesuitas de Tacna. A sus 92 años luce un aspecto físico erguido saludable. Su rostro muestra cierta dureza y energía probablemente por su pasado militar, pero que rápidamente se atenúan con su mirada empática. Se le observa cierta dificultad con su capacidad auditiva. Lo interrumpimos en un momento de descanso de su trajín diario que consiste principalmente en actividades educativas en el Colegio Miguel Pro. Visita algunas familias con las que comparte momentos gratos, especialmente cuando canta en hawaiano a sus "nietas". Se niega, por su fortaleza, al retiro definitivo. A continuación algunos fragmentos de la entrevista.

\section{¿Como encontró su vocación del camino de Dios, del camino religioso?}

Bueno, durante la segunda guerra mundial, yo estuve en el Pacífico sur donde estaban los japoneses, nuestra misión era bombardear sus bases para que no pudieran avanzar, los teníamos aislados, y debíamos seguir bombardeando. Cuando terminó mi misión, esta coincidió con el término de la guerra. Regresé a los Estados Unidos. Sentí un alivio tremendo y pensé que había que hacer algo positivo por la vida luego de estar destruyendo, matando. Me hice amigo del capellán de mi cuadrilla y él influyo tremendamente en mí. Cuando terminó la guerra busqué mi vocación y esa experiencia me motivó a pensar seriamente en ser sacerdote. Un poco después fui a la Universidad de los Jesuitas en San Francisco.

\section{¿Hubo alguna experiencia durante ese tiempo que lo marcó?}

Eso es difícil de decirlo, no creo que hubo una experiencia particular.. En realidad era la acumulación de experiencias, como por ejemplo, los vuelos de bombardeo contra el enemigo. Un año constante de bombardeos en donde había que tener tiempo para pensar en hacer algo en la vida. Muy cerca de ni carpa había un capellán, su amistad influyo en mi, quería trabajar como él.

\section{¿Cuál fue la influencia de sus padres en su vocación?}

No estaba convencidos de que debiera ser jesuita, pero no se oponían a ello.

\section{¿Por qué ser jesuita?}

En el seminario jesuita se enseñaba todo en latín y me dijeron que tenía que prepararme. Decidí conseguir una beca del gobierno, pues había servido en las fuerzas armadas. Hice contacto con la Universidad de San Francisco de jesuitas, en donde me ayudaron a definir mi vocación, luego de cuatro meses.

\section{¿Cómo fue la experiencia de venir a Tacna?}

Vinimos a Tacna dos jesuitas, yo tenía como 40 y el otro 60 . Me adapté bastante rápido y me hice amigo de ellos, encontré un ambiente bueno, allá por 1959 y en 1962 empecé con la obra Cristo Rey, con lo que me puse en contacto mas profundo con la vida familiar y con los jóvenes.

\section{¿Qué había que cambiar?}

Veía que el tacneño, en general, no iba a la misa dominical, pero con los años eso se fue cambiando. La experiencia de la ocupación extranjera, durante la guerra, explica que los tacneños no querían tener contacto con extraños, con los que no eran peruanos.

\section{¿Como puede resumir su obra en Tacna?}

Bueno, creo que a través de nuestros colegios hemos influido positivamente en la juventud que ha venido a estudiar en ellos. En la mayoría de los estudiantes hemos dejado una huella, creo que Cristo Rey es una obra que valía la pena. Algo que me da gusto es que algunos de los ex alumnos me invitan a reunirnos, eso es un indicio de que puedo acercarme a ellos y ellos a mi; es una gran satisfacción tener contacto con los ex alumnos.

¿Hay mucha gente que ve en usted un ejemplo, ven en usted un maestro ideal, qué reflexión le merece?

Qué mejor manera de saber que uno está influyendo positivamente en los jóvenes, me da mucha 
satisfacción parece que no estamos perdiendo el tiempo, aunque no todos son santos, hay muy buenos resultados.

\section{¿A sus 92 años se siente satisfecho de la labor cumplida?}

Sí, aunque pienso que se pudo hacer más, en general estoy bastante contento. Siento que he concluido un deber. El Cristo Rey es un buen colegio, hemos dejado buenos cimientos, no materiales, hemos sabido bien que es lo que queríamos para la formación cristiana, para el hombre de hoy.

\section{¿Por qué dedicarse a la educación?}

Cuando acabe el noviciado me enviaron a Puerto Rico, fue una experiencia dura donde tomé mucho interés en la educación. Comprendí lo valioso que puede ser influir en los jóvenes en su formación.

\section{¿Usted puede ser un Maestro de la Didáctica Universal aquel que predica con el ejemplo, que opinión le merece esto?}

Nuestra enseñanza en la formación de seres humanos, de buenos cristianos tiene que ser mucho más que enseñar matemáticas y otros cursos. Puedo utilizar los cursos como instrumentos de aprendizaje. Un buen maestro no solo da información, sino que está influyendo en sus alumnos por la manera en que enseña y como va dirigiendo sus cursos de tal manera que puedan tener un efecto positivo en ellos. No solo aprender de memoria, lo principal es tratar de cultivar principios humanos a través de los diversos cursos. Enseñar con el ejemplo revela que se tiene valores genuinos.

\section{¿La oración le ha ayudado en la vida?}

Sí, en muchos sentidos. Por ejemplo, puedo tener un pequeño fracaso y veo que la culpa es mía. ¿Qué es lo que debo hacer? Pedir ayuda a Dios, para cumplir con la vocación.

\section{¿Cual es su experiencia con el mar?}

Paz, reflexión, descanso. Cuando hablamos de mar pienso en mi sitio de nacimiento: Hawai, yo nací cerca del mar.

\section{¿Se ha sentido siempre cerca de Dios?}

No siempre. Es una gracia. Es algo donde no hay obligación. Siento que la gracia de Dios me esta ayudando.

\section{¿Con toda su experiencia, se siente usted en paz?}

Sí, yo creo que en este momento siento que Dios ha sido bueno conmigo, experimento bastante felicidad.

\section{REFERENCIAS BIBLIOGRÁFICAS}

Alarco von Perfall, C. (2011). Diccionario de la Psicología de C.G.Jung 1ra.ed. Universidad de San Martín de Porres Fondo Editorial.

Alarcón, R., Mazzotti, G., Nicolini, H. (2005). Psiquiatría 2da.ed. Organización Panamericana de la Salud.

Baron-Cohen, S. (2011). Empatía cero. Nueva teoría de la crueldad 1ra.ed. Alianza Editorial.

Campbell, J. (2011). El poder del mito 1ra. ed. Emece editores.

Carey, N. (2011). La revolución epigenética 1ra.ed. Biblioteca Buridán.

Chiappo, L. (1998). Honorio Delgado y la nobleza de ser hombre. En Revista de Neuropsiquiatría 61: 250-255.

Colegio Cristo Rey (1987), Los primeros 25 años.

Cyrulnik, B. (2013). Sálvate, la vida te espera 1ra.ed. Debate.

Dugatkin, L. (2007). Qué es el altruismo. La búsqueda científica del origen de la generosidad 1ra.ed. Katz Editores.

Geenen, G., Corveleyn, J. (2014). Vínculos protectores. Apego en padres e hijos en vulnerabilidad 1ra,ed, PUCP Fondo editorial.

Huizinga, J. (1972), Homo ludens 1ra.ed. Alianza Editorial.

Laing R.D. (1973), Experiencia y alienación en la vida contemporánea 2da.ed. Paidos.

León, R. (2010). La literatura psicológica del siglo $X X$ 1ra.ed. Universidad Ricardo Palma Editorial Universitaria.

Maturana, H., Verden-Zoller, G. (2013). Amor y juego. Fundamentos olvidados de lo humano. Desde el patriarcado a la democracia 1ra.ed. J,C.Saez editor.

Moneta, M. (2009). El apego. Aspectos clínicos y psicobiológicos de la díada madre-hijo 3ra.ed. Cuatro vientos editorial.

Rifkin, J. (2010). La civilización empática. La carrera hacia una conciencia global en un mundo en crisis 1ra.ed. Paidos.

Rizzolatti, G., Sinigaglia, C. (2006). Las neuronas espejo. Los mecanismos de la empatía emocional 1ra.ed. Paidos.

Vigotski, L. (2008). Imaginación y creación en la vida infantil 1 1ra.ed. Nueva Cultura 2008. 